\title{
IMPORTÂNCIA DOS NUTRIENTES NO EFLUENTE DE ÁGUAS RESIDUÁRIAS HUMANAS À SAÚDE PÚBLICA
}

\author{
IMPORTANCE OF NUTRIENTS IN THE EFFLUENT OF HUMAN WASTEWATER TO \\ PUBLIC HEALTH
}

\author{
P. M. P. BRANCO ${ }^{1 *}$, R. G. S. NOGUEIRA ${ }^{2}$, L. M. S. FERREIRA ${ }^{1}$, F. A. BORGES ${ }^{3}$, J. LUCAS JÚNIOR ${ }^{1}$
}

\section{RESUMO}

A presença de nutrientes pode constituir um problema nem sempre de fácil solução, uma vez que é necessário atender as exigências na Resolução CONAMA 357 para lançamentos em corpos d'água ou para adubação de solo. O presente estudo teve como objetivo avaliar a redução de nitrogênio e fósforo ( $\mathrm{N}$ e $\mathrm{P}$ ) do esgoto humano, do sistema de tratamento que é composto por um biodigestor tubular e uma lagoa de estabilização. As amostras foram colhidas semanalmente, totalizando 108 amostras do afluente do biodigestor e da lagoa de estabilização. As análises foram realizadas no Laboratório de Biomassa I do Departamento de Engenharia Rural da FCAV/UNESP - Câmpus de Jaboticabal. Para análise de $\mathrm{N}$ foi seguido metodologia descrita por Silva (1981) e para o P segundo Malavolta et al. (1991). Os padrões encontrados com relação ao N total, média no afluente de $95 \mathrm{mg} \mathrm{L}^{-1}$, com baixa eficiência de redução (afluente - lagoa), média de aproximadamente $44 \%$. O que pode ter sido influenciado pela pouca disponibilidade de matéria orgânica para os organismos que realizam a desnitrificação. Esta condição é desejável no sentido de reduzir a concentração de nitrato, que pode interferir na potabilidade da água. Com relação aos valores encontrados para o P total, cuja média no afluente foi de $374,28 \mathrm{mg} \mathrm{L}^{-1}$, com eficiência de redução (afluente - lagoa) em média de aproximadamente $82 \%$. O excesso de $\mathrm{P}$ justifica-se pela presença de detergentes superfosfatados e produtos químicos descartados na rede estudada. A elevada concentração N e P pode provocar a eutrofização do corpo receptor, o que favorece a proliferação de algas tóxicas (cianofíceas). Entretanto, como biofertilizante configura-se um excelente adubo orgânico em função da elevada disponibilidade de $\mathrm{N}$ e $\mathrm{P}$, aptos ao incremento na produtividade agrícola.

PALAVRAS-CHAVE: ALGAS TÓXICAS, BIOFERTILIZANTE, ESGOTO SANITÁRIO, EUTROFIZAÇÃO, SUSTENTABILIDADE AMBIENTAL

AGRADECIMENTOS: Cnpq e Copercana

ÁREA TEMÁTICA: Saúde Pública

\footnotetext{
${ }^{1}$ Faculdade de Ciências Agrárias e Veterinárias da Universidade Estadual Paulista (UNESP) - Câmpus de Jaboticabal * paulapilotto@ hotmail.com

${ }^{2}$ Faculdade de Zootecnia e Engenharia de Alimentos da Universidade de São Paulo (USP) - Câmpus de Pirassununga

${ }^{3}$ Faculdade de Medicina Veterinária e Zootecnia da Universidade Federal do Mato Grosso do Sul (UFMS) - Câmpus de Campo Grande
} 